\title{
Ventral tegmental area involvement in pair bonding in male prairie voles
}

\author{
J. Thomas Curtis *, Zuoxin Wang \\ Department of Psychology and Program in Neuroscience, Florida State University, 209 Copeland Ave., Tallahassee, FL 32306, USA
}

\begin{abstract}
Dopamine is known to play a critical role in social attachment in monogamous voles. However, little is known about the neurochemical regulation of central dopamine release during pair bond formation. Here we examine the effects on partner preference formation in male prairie voles of neurochemical manipulations in the ventral tegmental area (VTA), a major source of dopamine to brain regions implicated in pair bonding. Administration of NBQX, an AMPA receptor antagonist, or bicuculline, a GABA receptor antagonist, into the VTA induced partner preferences within $6 \mathrm{~h}$ in the absence of mating. We also found that, after unilateral administration of NBQX into the VTA, neuronal activation, as indicated by the expression of the immediate early gene c-fos, was decreased in the nucleus accumbens, prefrontal cortex, and medial amygdala, but was unchanged in the lateral septum and in a control region, the arcuate nucleus. These results confirm a role for the VTA in partner preference formation in monogamous voles and extend the list of neurochemicals important in pair bonding to include glutamate and GABA.
\end{abstract}

(C) 2005 Elsevier Inc. All rights reserved.

Keywords: Mating systems; Glutamate; Monogamy; Microtus; Reward

\section{Introduction}

Prairie voles (Microtus ochrogaster) display characteristics associated with a monogamous life strategy including a lack of sexual dimorphism, biparental care of young, and the formation of pair bonds between males and females [19]. In the laboratory, pair bonds between male and female prairie voles are manifested by a robust preference to associate with the familiar partner versus with a conspecific stranger [19]. Importantly, such partner preferences are readily quantifiable and provide a benchmark by which the effects of experimental manipulations can be assessed.

Over the past several years it has become increasingly clear that dopamine plays a central role in pair bond formation in voles. Studies comparing monogamous and non-monogamous species of voles have identified differences in the functioning of dopamine systems [9] and in other neurotransmitter systems that interact with dopamine in the regulation of pair bonding $[30,31,46,51]$. To date most research into dopamine's role in pair bonding has focused on mesolimbic dopamine "reward" pathways, and in particular, on the ventral striatum/nucleus accumbens (NAcc). The release of dopamine within the NAcc

\footnotetext{
* Corresponding author. Tel.: +1 850645 5615; fax: +1 8506447739 .

E-mail address: tcurtis@psy.fsu.edu (J.T. Curtis).
}

is thought to be rewarding and thus could mediate a positive association with the familiar partner in a pair bond [28]. Indeed, it has been shown that activation of the D2 sub-type of dopamine receptors within the NAcc is critical for pair bond formation in both sexes of prairie voles $[1,20]$. Further, pair bond formation results in modifications of the NAcc dopamine system that may serve to maintain a monogamous mating system [2].

Together these studies have established dopamine as being critical for pair bonding. However, a thorough understanding of the role of dopamine in pair bonding requires understanding dopamine sources as well as dopamine targets. The ventral tegmental area (VTA) is a major source of dopamine within the brain and several lines of evidence suggest that the VTA may play an important role in pair bonding. First, the VTA has been implicated in reward pathways that may be important in pair bonding. For example, rats and mice will self-administer drugs into the VTA [12-14,27] and drugs administered into the VTA can induce place preferences [6]. Second, mating activates the VTA in both sexes $[3,24,25]$ and is known to facilitate the formation of pair bonds in voles $[48,49]$. Third, the VTA projects to [43] brain regions that have been implicated in pair bond formation such as the amygdala, lateral septum, prefrontal cortex, and NAcc [1,15,20,32,34,51], while brain regions implicated in pair bonding, in turn, can influence the 
VTA $[17,18]$. Finally, stress, which affects pair bonding in monogamous voles [16], also alters the activity of dopaminergic cells within the VTA [40]. Thus, the VTA may represent an important point of convergence for processes critical for pair bond formation.

Neurochemical regulation of dopaminergic output from the VTA is complex and the effects of pharmacological manipulations within the VTA vary depending on the targets of the VTA projections. For example, administration of glutamate receptor antagonists into the VTA can decrease dopamine release in the frontal cortex while increasing dopamine release in the NAcc [45]. In areas such as the NAcc where dopamine release is under tonic inhibitory control, the effect of glutamate receptor blockade on dopamine release is thought to involve a reduction of the activity of GABAergic interneurons in the VTA that, in turn, modulate the activity of dopaminergic cells [13]. This idea is supported by evidence that administration of GABA agonists into the VTA can decrease extracellular dopamine levels within the NAcc $[22,50]$ and that rats will self-administer glutamate antagonists or GABA receptor antagonists, but not GABA agonists [27] into the VTA. GABA modulation of dopamine function also is supported by evidence that systemic administration of the dopamine antagonist sulpiride blocks the rewarding effects of GABA receptor blockade [12]. Finally, GABA agonists reduce the rewarding effects of self-stimulation within the ventral pallidum [38], further suggesting that GABAergic modulation of the dopamine system affects reward pathways.

Given the critical role for central dopamine in pair bonding, and the importance of processes within the VTA in regulating dopamine release, the goal of the present study was to examine a potential role for the VTA in pair bond formation in monogamous voles. We first examined the effects on pair bond formation of blockade of glutamate and GABA receptors in the VTA. We then used immunocytochemical visualization of the protein product of the immediate early gene c-fos to assess patterns of neuronal activation after glutamate receptor blockade.

\section{Methods}

Subjects were male offspring of the F4 generation of a laboratory colony of prairie voles originating from Illinois. After weaning at about 21 days of age, pups were kept in samesex sibling pairs until used in experiments. All animals were housed in plastic shoebox style cages $(29 \times 19 \times 13 \mathrm{~cm})$ under a 14:10 light: dark cycle with ad libitum food and water. All subjects were about 70 days of age at the time of the experiments.

\subsection{Brain cannulation}

Males were outfitted with bilateral 26 gauge guide cannulae (Plastics One, Roanoke, VA, USA) placed $1 \mathrm{~mm}$ dorsal to the VTA (stereotaxic coordinates from Bregma: $3.5 \mathrm{~mm}$ caudal, $0.6 \mathrm{~mm}$ bilateral, $5.1 \mathrm{~mm}$ ventral, Incisor Bar at $-2.5 \mathrm{~mm}$ ) under sodium pentibarbitol ( $1 \mathrm{mg} / 10 \mathrm{~g}$ body weight) anesthe- sia. Males were allowed three days of post-surgical recovery in the presence of the sibling.

\subsection{Behavioral testing}

On the test day, animals were randomly assigned to groups that received VTA administration of vehicle $(100 \mathrm{nl} /$ side of a salt solution isotonic for $\mathrm{Na}^{+}, \mathrm{Mg}^{++}, \mathrm{Ca}^{++}$, and $\mathrm{K}^{+}$[42], $n=8$ ), or of vehicle containing $10 \mathrm{ng}$ of the AMPA receptor antagonist NBQX (tetrahydro-6-nitro-2,3-dioxo-benzol[f]quinoxaline-7sulfonamide disodium salt, Sigma, $n=8$ ), or $5 \mathrm{ng}$ of the $\mathrm{GABA}_{\mathrm{A}}$ receptor antagonist bicuculline (Sigma, $n=7$ ). Drug dosages were based on reported effective doses in other models employing site-specific central administration of these compounds $[12,26]$. Drug administration was via injection cannulae that extended $1 \mathrm{~mm}$ beyond the end of the guide cannulae. Drug solutions were administered bilaterally at a rate of $50 \mathrm{nl} /$ min for 2 min using a syringe pump. Immediately following treatment, each male was paired with an ovariectomized female for $6 \mathrm{~h}$ in a clean cage containing food and water. We and others have previously shown that $6 \mathrm{~h}$ of non-sexual cohabitation does not induce partner preferences in male prairie voles $[20,29,47,48]$. Throughout the cohabitation period, the animals' interactions were videotaped (Panasonic 12:1 compression time-lapse video recorder and low-light camera) and the tapes subsequently were examined to verify the absence of mating.

At the end of the $6 \mathrm{~h}$ cohabitation period, each male was tested for a partner preference. The apparatus for the partner preference test consisted of a central cage $(20 \times 25 \times 45 \mathrm{~cm})$ joined by hollow tubes $(7.5 \times 16 \mathrm{~cm})$ to two identical parallel cages. One of these latter cages contained the familiar female partner, and the other contained an ovariectomized unfamiliar female. The females were tethered to restrict their movements to their respective cages and thus had no direct contact with each other. The male was released into the central cage and had free access to all cages. All cages contained food and water. A customized computer program (R. Henderson, Florida State University) using a series of light beams across the connecting tubes was used to monitor movement of the male among the cages. The computer program recorded the amount of time the male spent in each cage and the number of transits between cages. Throughout the test, the animals again were videotaped for behavioral analysis. Variables included the time spent by the male in each female's cage, number of transits between cages (measures of activity to ensure that treatments did not affect locomotor behavior), and the frequency and amount of time the male spent in direct contact with each female. The amount of time males spent in the neutral cage was assessed as a measure of time spent in isolation. Each test lasted for $3 \mathrm{~h}$. For each group, comparisons of time spent in direct contact with the partner vs. that with the stranger (partner preference) were made using paired $t$-tests. Between groups treatment effects on other behavioral measures were evaluated using one-way ANOVA. After all behavioral testing was completed, subjects were overanesthetized, and the brains removed. Cannula 
placement within the VTA was verified in $40 \mu \mathrm{m}$ coronal sections spanning the rostral-caudal extent of the ventral mid-brain.

\subsection{Tyrosine hydroxylase immunocytochemistry}

The distribution of putative dopaminergic cells in the ventral mid-brain has not previously been established in voles. Thus, to better allow us to assess cannula placement, we first needed to map the catecholaminergic cells that comprise the VTA. Brain sections at $120 \mu \mathrm{m}$ intervals from six male prairie voles were processed for immunocytochemical visualization of tyrosine hydroxylase $(\mathrm{TH})$, the rate-limiting enzyme in catecholamine biosynthesis.

Animals were perfused trans-cardially with ice-cold $0.9 \%$ $0.1 \mathrm{M}$ phosphate buffered saline (PBS, $\mathrm{pH}$ 7.4) followed by $\sim 120 \mathrm{ml}$ of cold $4 \%$ paraformaldehyde in PBS. After perfusion the brains were removed and placed in cold fixative for $2 \mathrm{~h}$ followed by immersion in 30\% sucrose in PBS. Brains then were sectioned at $40 \mu \mathrm{m}$ using a cryostat and the sections stored in PBS containing 1\% sodium azide until processed.
Floating sections were rinsed in $0.05 \mathrm{M}$ Tris- $\mathrm{NaCl}$ (TBS, $\mathrm{pH} 7.6$ ), incubated in $0.5 \% \mathrm{H}_{2} \mathrm{O}_{2}$ for $30 \mathrm{~min}$, rinsed in TBS, and then incubated in TBS with $0.5 \%$ Triton X-100 (TBS-t) containing $10 \%$ normal goat serum (NGS) for $1 \mathrm{~h}$. Tissue was incubated in the primary antibody (rabbit anti-rat-TH, (Chemicon) diluted 1:1000 in TBS-t) for $48 \mathrm{~h}$ at $4{ }^{\circ} \mathrm{C}$ and then at room temperature for $30 \mathrm{~min}$, followed by rinses in TBS-t containing $2 \%$ NGS. Tissue was placed in the secondary antibody (Cy-3 tagged donkey anti-rabbit IgG (Jackson Immuno) diluted 1:2000 in TBS-t with 2\% NGS) for $2 \mathrm{~h}$ followed by rinses in TBS and then in PBS. Sections were mounted on slides, allowed to dry, placed in xylene for 5 min, and cover-slipped using Permount (Fisher Scientific). The presence and distribution of TH-immunoreactive (Th-ir) staining within the ventromedial midbrain was assessed using an excitation of $650 \mathrm{~nm}$.

\subsection{Fos immunoctoychemistry}

Males were implanted with bilateral guide cannulae aimed at the VTA and allowed three days of post-surgical recovery. Since the majority of VTA projections to areas of interest in
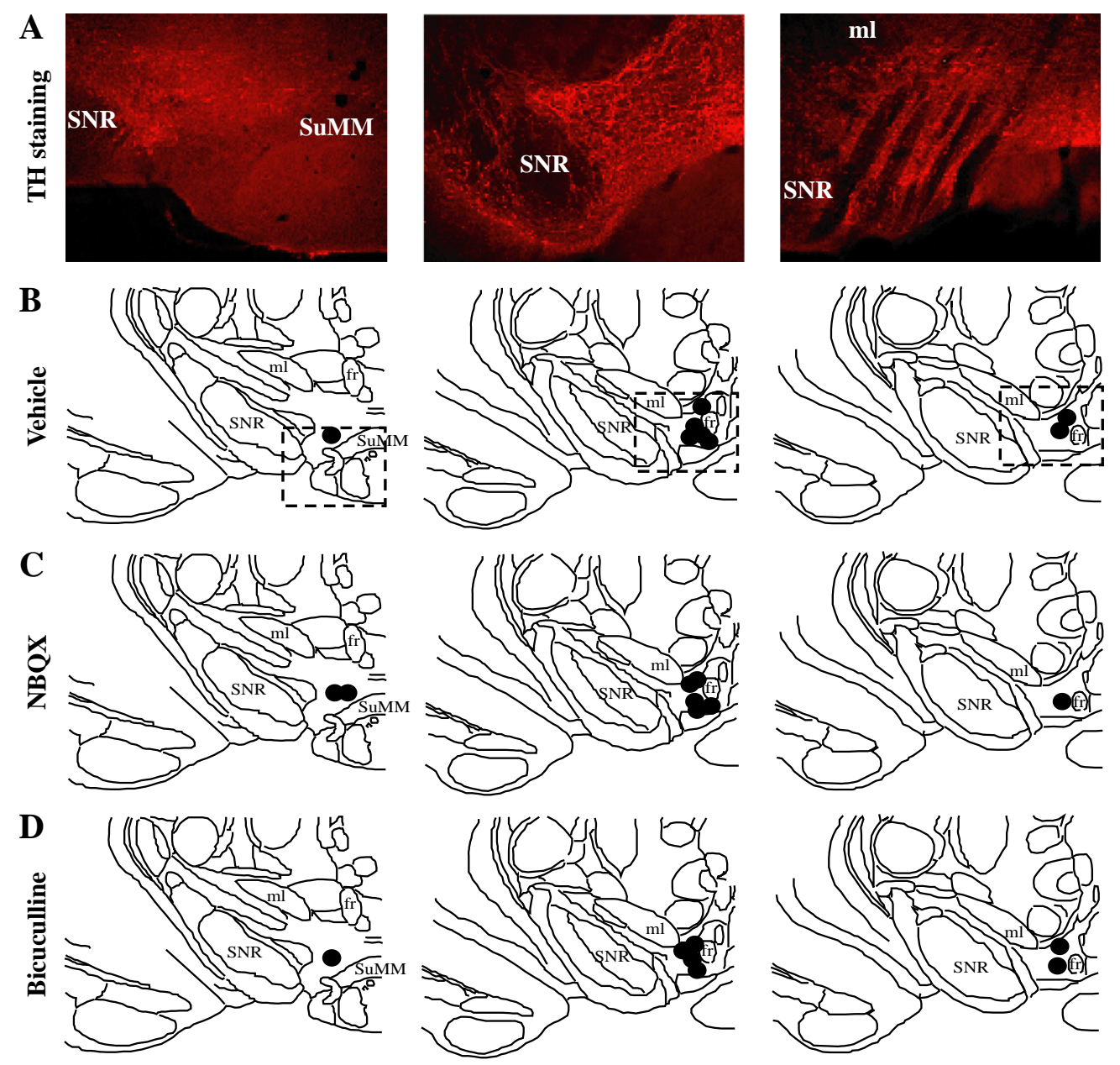

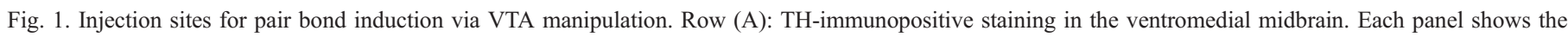

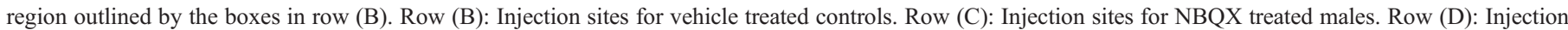

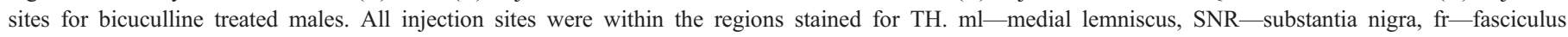
retroflexus, SuMM-supramammillary nucleus. 
the current study are ipsilateral [43] we chose to restrict injections to one hemisphere. We also chose to concentrate our analysis on the effects of glutamate receptor blockade since both tonic excitatory and inhibitory influences in dopamine release from VTA involve glutamatergic mechanisms [45]. Thus, on the test day seven males received $100 \mathrm{nl}$ of vehicle containing $10 \mathrm{ng}$ of NBQX into the left VTA, and $100 \mathrm{nl}$ of vehicle only into the right VTA. Six other males received the same treatment, but in these males cannula placement was $1 \mathrm{~mm}$ caudal to that in experimental males to provide a control for site specificity. Males then were placed individually in clean cages where they remained undisturbed for the remainder of the test. Ninety minutes after drug treatment, males were perfused and the brains prepared and sectioned as outlined above except that the brain sections spanning the rostral-caudal extent of the VTA were thawmounted on microscope slides for verification of cannula placement as outlined earlier.

Brain sections at $120 \mu \mathrm{m}$ intervals then were processed for immunocytochemical visualization of fos, the protein product of the immediate early gene c-fos. Floating sections were rinsed in $0.1 \mathrm{M}$ PBS, incubated in $0.5 \% \mathrm{H}_{2} \mathrm{O}_{2}$ in PBS for $30 \mathrm{~min}$, rinsed in PBS, and then incubated in PBS with $0.5 \%$ Triton X-100 (PBS- $t$ ) containing 10\% normal goat serum (NGS) for $1 \mathrm{~h}$. Tissue was incubated in the primary antibody (rabbit anti-rat-fos, Santa Cruz, cat. \# SC-52, diluted 1:30,000 in PBS-t with 2\% NGS) overnight at 4 ${ }^{\circ} \mathrm{C}$, followed by rinses in PBS-t containing 2\% NGS. Tissue was placed in the secondary antibody (biotinylated goat-antirabbit, diluted 1:300 in PBS-t containing 2\% NGS) for 2 $\mathrm{h}$ followed by rinses in PBS. Sections were incubated in an avidin-biotin-peroxidase conjugate (Vector Laboratories) in PBS, and then rinsed in PBS. Staining was visualized by reacting the tissue with $3,3^{\prime}$-diaminobenzidine hydrochloride and $0.04 \%$ nickel ammonium sulfate followed by rinses in PBS. Sections were mounted on slides, allowed to dry, cover slipped using Permount, and examined microscopically.

\subsection{Analysis of fos expression}

We examined c-fos expression in the NAcc, medial amygdala (mAMG), lateral septum (LS) and prefrontal cortex (PFC), all of which are forebrain areas previously implicated in social behavior in voles $[1,10,20,31,34,35,52]$, and in the arcuate nucleus, an area not known to play a role in pair bonding. Fos immunoreactive (fos-ir) cells were quantified using computerized software (NIH Image). Particle density and maximum and minimum particle size were adjusted based on comparisons with visual counts. Briefly, fos-ir nuclei were counted by eye on random sections and the results compared with those from computer analysis. The computer parameters were then adjusted such that similar counts were produced. This process was repeated until the visual counts and computer generated counts were consistently similar (typically within 1-2\%). For each animal, representative sections from each area (4-7 sections depending on area, anatomically matched between animals) were analyzed and the total number of fos-ir nuclei throughout the rostral-caudal extent of each area was recorded. Counts for each hemisphere were totaled separately and the data were expressed as a ratio of the number of fos-ir nuclei on the side receiving the NBQX and the number seen on the vehicle treated side for each area.

Data analysis consisted of comparing the NBQX side/ vehicle side ratios for each brain area between animals in which NBQX was administered into the VTA and those in which NBQX was injected into the control region. Two-way (brain area $\times$ treatment) analysis of variance was used to assess main effects and, where main effects were found, a Duncan's test was used to assess specific differences.

\section{Results}

\subsection{Partner preference induction}

Extensive TH-ir staining was found throughout the ventromedial mid-brain, (Fig. 1A). Assessment of cannula placement showed that, with one exception, cannulae were placed within the TH-ir region that comprises the VTA (Fig. 1B-D). The animal with the misplaced cannula was not included in the final analysis.

In preliminary tests, $100 \mathrm{ng}$ NBQX or $50 \mathrm{ng}$ bicuculline caused the animals to display reduced locomotor activity and a tendency to remain in isolation. Reducing the doses tenfold eliminated these confounds. Male prairie voles treated with either NBQX (10 ng) or with bicuculline (5 ng) spent significantly more time in contact with the familiar partner than with the stranger (Fig. 2). Males receiving vehicle treatment were equally likely to associate with the stranger as with the partner. Other behavioral measures are shown in Table 1. There was a main effect of treatment on the combined amount of time males spent in contact with the stimulus females $(F 2,22=3.71, p<0.05)$. Males treated with NBQX spent more time in close contact with females than did males treated with bicuculline; however, neither group differed from control males. Perhaps as a consequence of the NBQX-treated

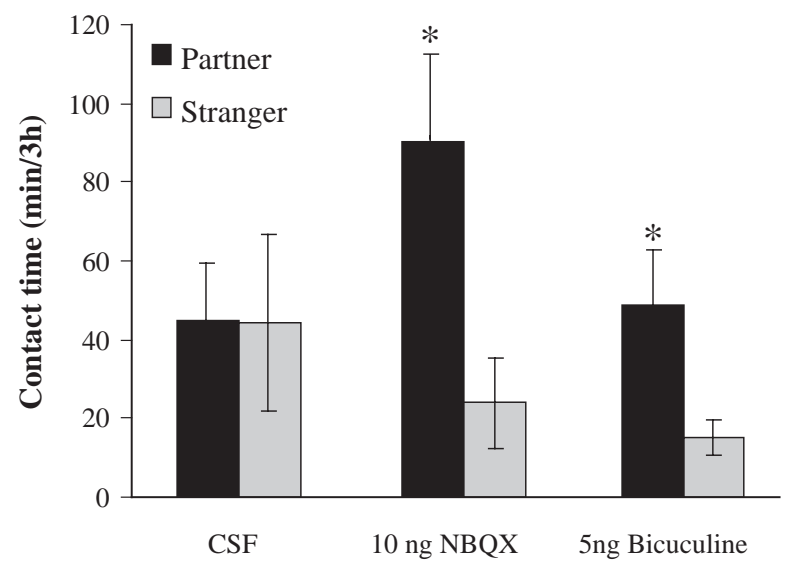

Fig. 2. When injected into the VTA, both NBQX and bicuculline were capable of inducing pair bonds in male prairie voles. *Significantly more time spent in contact with the familiar partner than with the stranger. 
Table 1

Comparisons (mean $\pm \mathrm{SEM}$ ) of total time spent in contact with the stimulus females, time spent in isolation, and locomotor activity of male prairie voles after VTA manipulations

\begin{tabular}{lclr}
\hline Treatment & $\begin{array}{l}\text { Contact time } \\
(\mathrm{min})\end{array}$ & $\begin{array}{l}\text { Isolation } \\
(\mathrm{min})\end{array}$ & \multicolumn{1}{c}{$\begin{array}{l}\text { Cage crossing } \\
(\text { number })\end{array}$} \\
\hline Vehicle & $92.3 \pm 9.7$ & $36.9 \pm 9.1$ & $76.9 \pm 16.4$ \\
NBQX & $117.5 \pm 12.2$ & $13.3 \pm 2.1$ & $81.8 \pm 14.5$ \\
Bicuculline & $75.1 \pm 9.6$ & $31.6 \pm 9.1$ & $141.0 \pm 33.2$
\end{tabular}

* NBQX and bicuculline treated males differed in total time spent in contact with the stimulus animals, but neither differed from control males.

males spending more time in contact with the females, these males tended to spend less time in isolation than did control males or males receiving bicuculline, however, this effect did not achieve statistical significance $(F 2,22=2.72, p=0.09)$. No treatment effects were seen for locomotor activity $(F 2,22=$ 2.33, $p=0.12$ ).

\section{2. fos induction after $N B Q X$}

Injection sites for fos-induction were confined to the same regions as those used for pair bond induction while control injections were well outside of the VTA (Fig. 3). Nuclei positive for fos-ir were present in all areas assessed (Fig. 4). Two males (one from each treatment group) were excluded from the analysis due to abnormally low numbers of fos-ir nuclei, and another (from the VTA injected group) due to an excessively high number of fos-ir nuclei. Two-way ANOVA revealed main effects of treatment $(\mathrm{NBQX}$ injected into the VTA vs. into control sites; $F 1,40=7.51, p<0.01$ ), brain region $(F 4,40=3.09, p<0.03)$, and an interaction $(F 4,40=3.12$, $p<0.03$ ). In the PFC (Fig. 4A-D), NAcc, and mAMG the ratio of fos-ir cells in animals in which NBQX was injected into the VTA was lower than that in males in which NBQX was injected into control sites (Fig. 5). There were no differences between the ratios of VTA vs. control injected groups in the LS or arcuate nucleus (Figs. 4E, F, and 5). There were no significant differences between the NBQX/vehicle ratios for any brain region in the group that received injections into the control region.

\section{Discussion}

The formation of a selective preference for association with a familiar partner is a critical step in the formation of monogamous pair bonds. It is well-established that dopamine plays a role in the regulation of partner preference formation in monogamous voles. Blockade of the D2 family of dopamine receptors in NAcc inhibits the formation of partner preferences in prairie voles of both sexes, while activation of D2-type receptors is capable of inducing partner preferences under conditions where such preferences do not normally form $[2,20]$. Although these studies have established a role for dopamine in pair bonding, little is known about the control of dopamine release during pair bond formation. The VTA is a major source of the dopamine that is released into the NAcc, as well as into other brain regions implicated in pair bonding. Here we report that blockade of either AMPA type glutamate receptors or of $\mathrm{GABA}_{\mathrm{A}}$ receptors within the VTA can induce partner preference formation in monogamous prairie voles. In addition, we show region specific changes in neuronal activation in brain regions implicated in pair bonding after AMPA receptor blockade in the VTA.

\subsection{Partner preference induction}

The distribution of TH-ir staining in the VTA in the prairie vole is similar to that described for rat [43]. Since the VTA
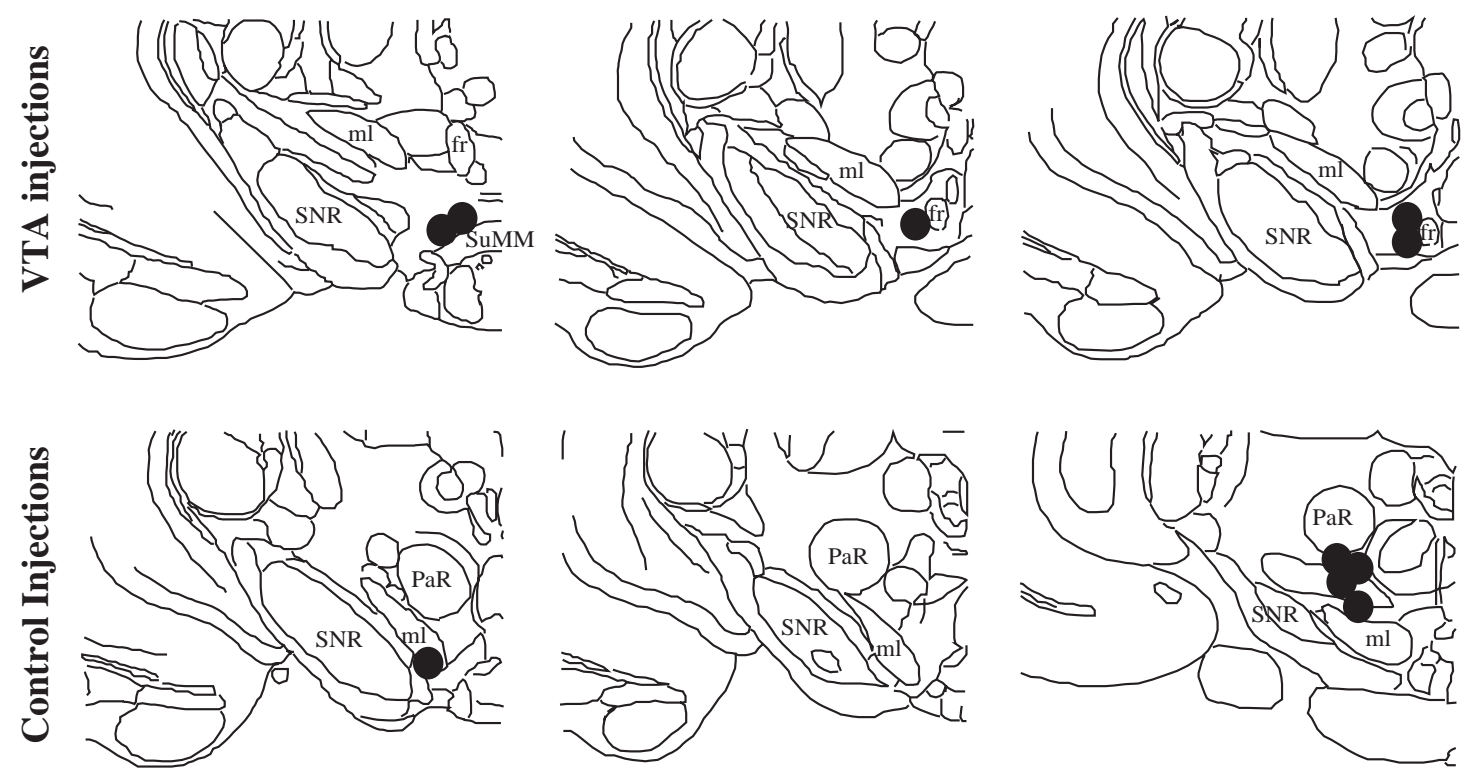

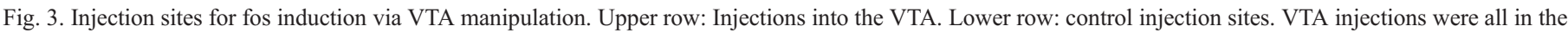

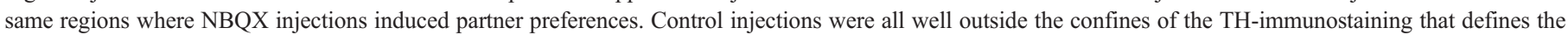
VTA. ml—medial lemniscus, SNR — substantia nigra, fr—fasciculus retroflexus, SuMM—supramammillary nucleus, PaR—pararubral nucleus. 


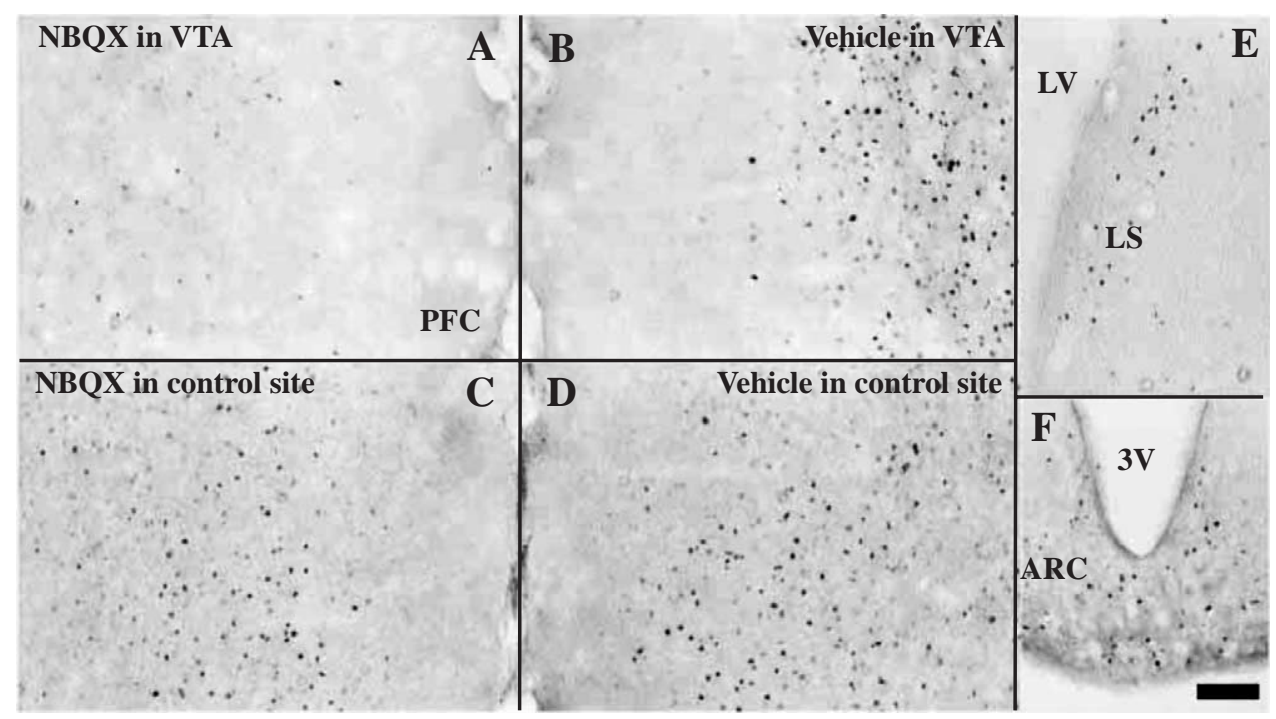

Fig. 4. Patterns of neuronal activation associated with AMPA receptor blockade in VTA. Panels (A) and (B) show the effects of unilateral NBQX administration into the VTA on fos expression in the PFC; panel (A) NBQX into left side of VTA, panel (B) vehicle into right side of VTA. Panels (C) and (D) show the corresponding results when NBQX was injected into control regions; panel (C) NBQX side, panel (D) vehicle side. Panel (C) shows a typical distribution of fos-ir nuclei in the lateral septum; fos-ir cells were concentrated near the lateral portions of LS. Panel (F) shows the uniform distribution of fos-ir nuclei in both the NBQX and vehicle treated sides of the arcuate nucleus. In panels $(\mathrm{A})-(\mathrm{E})$, the panel letter is placed nearest the midline; panel $(\mathrm{F})$ is centered on the midline. LV-lateral ventricle, $3 \mathrm{~V}-$ third ventricle, LS—lateral septum, PFC—prefrontal cortex, ARC—arcuate nucleus. Scale bar $=100 \mu \mathrm{m}$.

injection sites were confined to those areas where extensive TH-ir staining was found, we are confident that the manipulations that induced partner preferences were largely restricted to the VTA. It is unlikely that the partner preferences induced by either NBQX or bicuculline resulted from the actions of these drugs during the behavioral testing period. The effects of these drugs are manifested within the first $3 \mathrm{~h}$ after administration $[8,23,33,36,41]$. Since the partner preference tests were conducted between 6 and $9 \mathrm{~h}$ after drug administration, it is likely that these drugs were no longer exerting direct effects on behavior.

Control of dopamine release from VTA efferents is complex and, to a large extent, the effects of pharmacological manipulation of the VTA dopamine system depend on the

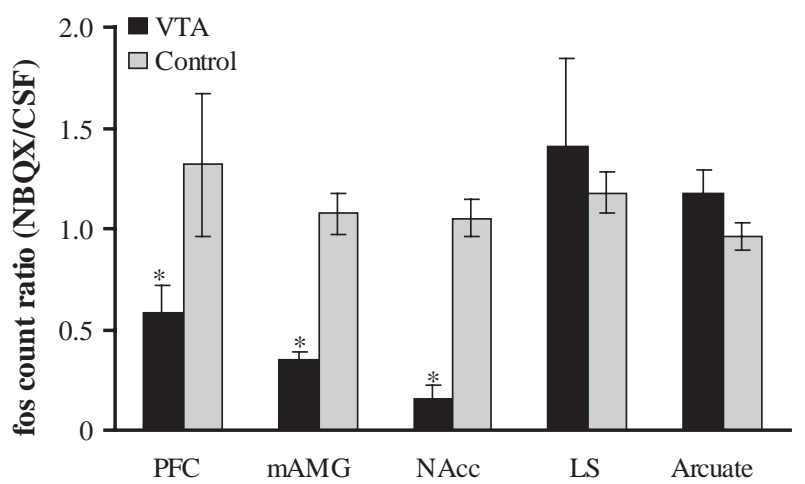

Fig. 5. Comparison of fos-ir ratios from male prairie voles injected unilaterally with NBQX into the VTA vs. those from males in which NBQX was injected caudal to the VTA. Each ratio represents group means ( \pm SEM) for the total numbers of fos-ir nuclei in each brain region for the hemisphere ipsilateral to the NBQX injection vs. the side contralateral to the NBQX injection. *ratio significantly lower in males in which NBQX was injected into the VTA than in males in which NBQX was injected into a control site. target region examined [45]. Dopamine release in the NAcc is under tonic inhibitory control via a glutamate-mediated mechanism within the VTA, with AMPA type receptors playing an especially important role in controlling normal physiological responses $[44,45]$. Our observation that blockade of AMPA receptors in the VTA induces partner preference formation is consistent with the idea that reduction of AMPA mediated tonic inhibition of VTA efferents to the NAcc results in increased dopamine release in the NAcc [34], which in turn is critical for pair bonding [1,20]. Since blockade of an excitatory influence results in an increase in dopamine release, it is likely that the glutamate receptors being impacted are on GABAergic interneurons [13]. Consistent with this idea is the suggestion that efferent (presumably glutamatergic [39]) projections from the PFC to the VTA may synapse on GABAergic interneurons that ultimately modulate dopamine release in the NAcc [7]. Our results are in accord with this interpretation since GABA receptor blockade also induced partner preferences. Thus, it is likely that the processes underlying pair bonding involve a reduction of excitatory input to the VTA that in turn reduces the activity of GABAergic cells within the VTA, ultimately increasing dopamine release in NAcc.

In contrast to the tonic inhibition of dopamine release from the VTA to the NAcc, there is glutamate-mediated tonic excitatory control of dopamine release from the VTA to the PFC [45]. Again, this is consistent with observations that PFC projections to VTA synapse on dopaminergic cells that project back to PFC [7]. Thus our observation that blockade of glutamate receptors induces partner preferences suggests that pair bond formation may involve a reduction in dopamine release in the PFC. Although the neuropeptide oxytocin has been shown to influence pair bonding via actions within the 
PFC [51], presumably through interaction with dopamine systems, a direct test of a role for PFC dopamine in pair bonding has not been conducted. It is possible that, in contrast to the inhibitory effects of dopamine receptor blockade in NAcc on pair bonding, such blockade in the PFC may induce pair bonding. It is important to note that blockade of AMPA receptors in the VTA also alters stress-induced dopamine release in the PFC [44], and we recently have shown that central dopamine interacts with corticosterone-mediated processes in the formation of pair bonds [11].

In addition to direct projections to the PFC and NAcc, the VTA may modulate activity in each of these areas indirectly via the amygdala. Both dopaminergic and non-dopaminergic projections from the VTA to the amygdala have been identified in other species [43]. The dopaminergic projections in particular are of interest since they are important in behavioral sensitization processes [4] that likely play a role in pair bonding. The amygdala in turn can modulate glutamate release in both the PFC and NAcc, and modulate dopamine release in the NAcc via a glutamate-mediated mechanism within the PFC [5]. Thus, the effects of VTA manipulations may occur by way of a complex interaction between direct and indirect influences on brain regions implicated in pair bonding.

\subsection{Neuronal activation patterns}

The patterns of fos-ir were compared between drug-injected and saline-injected hemispheres in the same animal. This type of intra-subject analysis provides excellent controls for surgical, handling, and injection effects. The lack of differences in neuronal activation between NBQX and vehicle treated sides in the LS and the arcuate nucleus indicate that the changes in $\mathrm{PFC}$, NAcc, and mAMG were not the result of global inactivation of one hemisphere due to unilateral injection of NBQX. The lack of effect on neuronal activation in controltreated males shows that effects of NBQX administration were specific to the VTA.

The glutamate-mediated opposite modulation of dopamine release in the PFC and NAcc [34], and the possibility of either inhibitory or excitatory inputs to the amygdala and LS [32], make interpretation of the neuronal activation patterns after NBQX treatment complicated. It must be noted that in discussing fos induction we are not assuming that a decrease in the number of fos-ir cells necessarily indicates inhibition. Where decreased fos-immunoreactivity is seen, it also is possible that NBQX treatment is blocking an excitatory influence and thus reducing neuronal activation that would normally occur under the handling conditions experienced by the voles. In addition, since detailed mapping of VTA projections has not been completed in voles, in discussing these results we will draw heavily on the description of this system in rat as described by Swanson [43].

A priori, it would be expected that AMPA receptor blockade in the VTA would decrease dopamine release in PFC and increase dopamine release in NAcc. Since the majority of projections from the VTA to the areas examined are ipsilateral [43], it would be expected that the number of fos-ir cells in
PFC would be lower in the NBQX treated side than in the control injected side, while the reverse should be true for NAcc. Our results showing that the number of fos-ir cells in the PFC were lower in the NBQX treated side than in the control side are consistent with such an expectation (Fig. 4A,B). However, the NBQX treated side also had fewer fos-ir cells in NAcc. There are several possible explanations for this finding. First, in addition to acting on GABAergic interneurons, the AMPA blockade may have acted on the small fraction of noncatecholaminergic cells that project from the VTA to NAcc [43], and it is blockade of the activity of these cells that resulted in less neuronal activation. Second, some portion of dopaminergic cells in the VTA respond to AMPA administration by increasing activity and release of dopamine into the NAcc $[21,53]$. Thus, the decrease in fos activation in the NAcc could reflect decreased dopamine release as result of AMPA receptor blockade. Such a result might suggest that AMPA receptor blockade and GABA receptor blockade are operating independently in the regulation of partner preference formation. Finally, the decrease in fos activation in the NAcc may actually reflect an inhibitory influence. It is known that D2type dopamine receptor agonists administered into the NAcc can produce partner preferences in male voles [2]. Since D2 activation often is associated with inhibition [37], the current results could reflect activation of post-synaptic D2 dopamine receptors. It is important to note that the treatment used in this portion of the study was shown to induce partner preferences in a separate group of males. Thus, these results suggest that reduced neuronal activation in these areas may contribute to pair bond formation.

Unlike the NAcc, which receives only a minor noncatecholaminergic input from the VTA, approximately half of the VTA projections to the amygdala are non-catecholaminergic [43]. Thus, the decrease in fos-ir in the mAMG also could result from decreased activity of either catecholaminergic or noncatecholaminergic projections from the VTA. The lateral septum also receives both catecholaminergic and non-catecholaminergic projections from the VTA [43]. In contrast to the NAcc, PFC, and mAMG, however, we found no difference in fos expression between the NBQX and control-treated sides. The explanation may lie in the distribution of fos-ir cells found in the present study. Swanson [43] noted that retrograde labeling from the LS was seen in the VTA only when label was placed in the medial portion of the LS. In the present study, very few fosir cells were seen in the medial LS. Rather, most fos-ir cells were adjacent to the ventricles (Fig. 4E). In addition, in the present study, the VTA injection sites may have been too far lateral to affect the majority of cells that project to the LS [43]. Given this information, it would be premature to conclude that VTA to LS projections play no role in pair bond formation.

Together, these results establish a role for the VTA in pair bond formation in monogamous rodents and extend the list of neurochemicals involved in pair bonding to include glutamate and GABA. The results of the examination of neuronal activation associated with a treatment that induces pair bonds in prairie voles suggests that, in some brain regions, a reduction of neuronal activity may play a role in pair bond formation. 


\section{Acknowledgements}

We thank Mr. Michael Smeltzer, Mr. Kyle Gobrogge, and Dr. Kathleen Curtis for helpful suggestions. This work was supported by National Institutes of Health grants NICHD 40722 (JTC) and NIMH 58616 and NIMH 66734 (ZW).

\section{References}

[1] Aragona BJ, Liu Y, Curtis JT, Stephan FK, Wang Z. A critical role for nucleus accumbens dopamine in partner-preference formation in male prairie voles. J Neurosci 2003;23:3483-90.

[2] Aragona BJ, Liu Y, Wang ZX. Nucleus accumbens dopamine is important for social choice and the maintenance of social bonds. Program No. 757.7. 2003 Abstract Viewer/Itinerary Planner. Washington, DC: Society for Neuroscience; 2003.

[3] Balfour ME, Yu L, Coolen LM. Sexual behavior and sex-associated environmental cues activate the mesolimbic system in male rats. Neuropsychopharmacology 2004;29:718-30.

[4] Bjijou Y, De Deurwaerdere P, Spampinato U, Stinus L, Cador M. Damphetamine-induced behavioral sensitization: effect of lesioning dopaminergic terminals in the medial prefrontal cortex, the amygdala and the entorhinal cortex. Neuroscience 2002;109:499-516.

[5] Burns LH, Robbins TW, Everitt BJ. Differential effects of excitotoxic lesions of the basolateral amygdala, ventral subiculum and medial prefrontal cortex on responding with conditioned reinforcement and locomotor activity potentiated by intra-accumbens infusions of Damphetamine. Behav Brain Res 1993;55:167-83.

[6] Byrne R, Harris G, Aston-Jones G. Glutamate input to the ventral tegmental area is necessary for both learning and expression of morphine place preference. Program No. 110.1. 2003 Abstract Viewer/Itinerary Planner. Washington, DC: Society for Neuroscience; 2003.

[7] Carr DB, Sesack SR. Projections from the rat prefrontal cortex to the ventral tegmental area: target specificity in the synaptic associations with mesoaccumbens and mesocortical neurons. J Neurosci 2000;20: $3864-73$.

[8] Cole RL, Sawchenko PE. Neurotransmitter regulation of cellular activation and neuropeptide gene expression in the paraventricular nucleus of the hypothalamus. J Neurosci 2002;22:959-69.

[9] Curtis JT, Stowe JR, Wang Z. Differential effects of intraspecific interactions on the striatal dopamine system in social and non-social voles. Neuroscience 2003;118:1165-73.

[10] Curtis JT, Wang Z. Forebrain c-fos expression under conditions conducive to pair bonding in female prairie voles (Microtus ochrogaster). Physiol Behav 2003;80:95-101

[11] Curtis JT, Wang Z. Acute glucocorticoid receptor blockade induces pair bonds in female prairie voles. Program No. 215.8. 2004 Abstract Viewer/Itinerary Planner. Washing, DC: Society for Neuroscience, (2004)

[12] David V, Durkin TP, Cazala P. Self-administration of the GABAA antagonist bicuculline into the ventral tegmental area in mice: dependence on D2 dopaminergic mechanisms. Psychopharmacology (Berl) 1997; 130:85-90.

[13] David V, Durkin TP, Cazala P. Rewarding effects elicited by the microinjection of either AMPA or NMDA glutamatergic antagonists into the ventral tegmental area revealed by an intracranial self-administration paradigm in mice. Eur J Neurosci 1998;10:1394-402.

[14] David V, Durkin TP, Cazala P. Differential effects of the dopamine D2/D3 receptor antagonist sulpiride on self-administration of morphine into the ventral tegmental area or the nucleus accumbens. Psychopharmacology (Berl) 2002;160:307-17.

[15] de Vries GJ, Miller MA. Anatomy and function of extrahypothalamic vasopressin systems in the brain. Prog Brain Res 1998;119:3-20.

[16] DeVries AC, DeVries MB, Taymans SE, Carter CS. The effects of stress on social preferences are sexually dimorphic in prairie voles. Proc Natl Acad Sci U S A 1996;93:11980-4.
[17] Georges F, Aston-Jones G. Potent regulation of midbrain dopamine neurons by the bed nucleus of the stria terminalis. J Neurosci 2001; 21:RC160.

[18] Georges F, Aston-Jones G. Activation of ventral tegmental area cells by the bed nucleus of the stria terminalis: a novel excitatory amino acid input to midbrain dopamine neurons. J Neurosci 2002;22:5173-87.

[19] Getz LL, Carter CS, Gavish L. The mating system of the prairie vole, Microtus ochrogaster: field and laboratory evidence for pair-bonding. Behav Ecol Sociobiol 1981;8:189-94.

[20] Gingrich B, Liu Y, Cascio C, Wang Z, Insel TR. Dopamine D2 receptors in the nucleus accumbens are important for social attachment in female prairie voles (Microtus ochrogaster). Behav Neurosci 2000; 114:173-83.

[21] Giorgetti M, Hotsenpiller G, Ward P, Teppen T, Wolf ME. Amphetamineinduced plasticity of AMPA receptors in the ventral tegmental area: effects on extracellular levels of dopamine and glutamate in freely moving rats. J Neurosci 2001;21:6362-9.

[22] Guan XM, McBride WJ. Serotonin microinfusion into the ventral tegmental area increases accumbens dopamine release. Brain Res Bull 1989;23:541-7.

[23] Harte M, O'Connor WT. Evidence for a selective prefrontal cortical gaba(b) receptor-mediated inhibition of glutamate release in the ventral tegmental area: a dual probe microdialysis study in the awake rat. Neuroscience 2005;130:215-22.

[24] Holstege G, Georgiadis JR, Paans AM, Meiners LC, van der Graaf FH, Reinders AA. Brain activation during human male ejaculation. J Neurosci 2003;23:9185-93.

[25] Holstege G, Reinders AAT, Paans AMJ, Meiners LC, Pruim J, Georgiadis JR. Brain activation during female sexual orgasm. Program No. 727.7. 2003 Abstract Viewer/Itinerary Planner. Washington, DC: Society for Neuroscience; 2003

[26] Ikeda H, Akiyama G, Fujii Y, Minowa R, Koshikawa N, Cools AR. Role of AMPA and NMDA receptors in the nucleus accumbens shell in turning behaviour of rats: interaction with dopamine receptors. Neuropharmacology $2003 ; 44: 81-7$

[27] Ikemoto S, Murphy JM, McBride WJ. Self-infusion of GABA(A) antagonists directly into the ventral tegmental area and adjacent regions. Behav Neurosci 1997;111:369-80

[28] Insel TR. Is social attachment an addictive disorder? Physiol Behav 2003;79:351-7.

[29] Insel TR, Hulihan TJ. A gender-specific mechanism for pair bonding: oxytocin and partner preference formation in monogamous voles. Behav Neurosci 1995;109:782-9.

[30] Insel TR, Shapiro LE. Oxytocin receptor distribution reflects social organization in monogamous and polygamous voles. Proc Natl Acad Sci U S A 1992;89:5981-5.

[31] Insel TR, Wang Z-X, Ferris CF. Patterns of brain vasopressin receptor distribution associated with social organization in microtine rodents. J Neurosci 1994;14:5381-92.

[32] Kirkpatrick B, Carter CS, Newman SW, Insel TR. Axon-sparing lesions of the medial nucleus of the amygdala decrease affiliative behaviors in the prairie vole (Microtus ochrogaster): behavioral and anatomical specificity. Behav Neurosci 1994;108:501-13.

[33] Li Y, Vartanian AJ, White FJ, Xue CJ, Wolf ME. Effects of the AMPA receptor antagonist NBQX on the development and expression of behavioral sensitization to cocaine and amphetamine. Psychopharmacology (Berl) 1997;134:266-76.

[34] Liu Y, Curtis JT, Wang Z. Vasopressin in the lateral septum regulates pair bond formation in male prairie voles (Microtus ochrogaster). Behav Neurosci 2001;115:910-9.

[35] Liu Y, Wang ZX. Nucleus accumbens oxytocin and dopamine interact to regulate pair bond formation in female prairie voles. Neuroscience 2003;121:537-44.

[36] Nakamura K, Kurasawa M, Shirane M. Impulsivity and AMPA receptors: aniracetam ameliorates impulsive behavior induced by a blockade of AMPA receptors in rats. Brain Res 2000;862:266-9.

[37] Nishi A, Snyder GL, Greengard P. Bidirectional regulation of DARPP-32 phosphorylation by dopamine. J Neurosci 1997;17:8147-55. 
[38] Panagis G, Kastellakis A. The effects of ventral tegmental administration of GABA(A), GABA(B), NMDA and AMPA receptor agonists on ventral pallidum self-stimulation. Behav Brain Res 2002;131:115-23.

[39] Rossetti ZL, Marcangione C, Wise RA. Increase of extracellular glutamate and expression of Fos-like immunoreactivity in the ventral tegmental area in response to electrical stimulation of the prefrontal cortex. J Neurochem 1998;70:1503-12.

[40] Saal D, Dong Y, Bonci A, Malenka RC. Drugs of abuse and stress trigger a common synaptic adaptation in dopamine neurons. Neuron 2003; 37:577-82.

[41] Sakai K, Akiyama K, Kashihara K, Tsuchida K, Ujike H, Kuroda S, et al. AMPA receptors modulate dopamine release in the striatum, as measured by brain microdialysis. Neurochem Int 1997;30:329-36.

[42] Sved AF, Curtis JT. Amino acid neurotransmitters in nucleus tractus solitarius: an in vivo microdialysis study. J Neurochem 1993;61:2089-98.

[43] Swanson LW. The projections of the ventral tegmental area and adjacent regions: a combined fluorescent retrograde tracer and immunofluorescence study in the rat. Brain Res Bull 1982;9:321-53.

[44] Takahata R, Moghaddam B. Glutamatergic regulation of basal and stimulus-activated dopamine release in the prefrontal cortex. J Neurochem 1998;71:1443-9.

[45] Takahata R, Moghaddam B. Target-specific glutamatergic regulation of dopamine neurons in the ventral tegmental area. J Neurochem 2000; $75: 1775-8$
[46] Wang Z, Young LJ, Liu Y, Insel TR. Species differences in vasopressin receptor binding are evident early in development: comparative anatomic studies in prairie and montane voles. J Comp Neurol 1997;378:535-46.

[47] Wang Z, Yu G, Cascio C, Liu Y, Gingrich B, Insel TR. Dopamine D2 receptor-mediated regulation of partner preferences in female prairie voles (Microtus ochrogaster): a mechanism for pair bonding? Behav Neurosci 1999;113:602-11.

[48] Williams JR, Catania KC, Carter CS. Development of partner preferences in female prairie voles (Microtus ochrogaster): the role of social and sexual experience. Horm Behav 1992;26:339-49.

[49] Winslow JT, Hastings N, Carter CS, Harbaugh CR, Insel TR. A role for central vasopressin in pair bonding in monogamous prairie voles. Nature 1993;365:545-8.

[50] Xi ZX, Stein EA. Nucleus accumbens dopamine release modulation by mesolimbic GABAA receptors - an in vivo electrochemical study. Brain Res 1998;798:156-65.

[51] Young LJ, Lim MM, Gingrich B, Insel TR. Cellular mechanisms of social attachment. Horm Behav 2001;40:133-8.

[52] Young LJ, Wang Z. The neurobiology of pair bonding. Nat Neurosci 2004;7:1048-54

[53] Zhang XF, Hu XT, White FJ, Wolf ME. Increased responsiveness of ventral tegmental area dopamine neurons to glutamate after repeated administration of cocaine or amphetamine is transient and selectively involves AMPA receptors. J Pharmacol Exp Ther 1997;281:699-706. 